\title{
Considerations about the Bibliometric Impact Factor. The BJCVS is on the Right Track
}

Paulo Roberto B. Evora' ${ }^{2}$ MD, PhD; Andreia C. Feitosa do Carmo², MSc; Camila Sáfadi Alves Gonçalves³; Domingo M. Braile ${ }^{4}, \mathrm{MD}, \mathrm{PhD}$

Bibliometric indicators are qualitative methods that allow the evaluation of scientific production through statistical techniques, and one of the most important indicators is the impact factor. The basis for the impact factor is the Journal Citation Report (JCR). Available from Clarivate Analytics, it was developed by Eugene Garfield in 1958, whose idea was to allow a practical analysis of the propagation of scientific information in their respective areas of knowledge. To do this, Garfield determined a numerator: the number of citations in the current year for any items published in the journal in the previous two years; and the denominator: the number of articles published in those two years ${ }^{[1,2]}$. The basic elements can be adapted to consider shorter or longer time intervals, according to the area of knowledge.

The metric was developed for responsible use in journal management, allowing librarians to evaluate and select which journals to sign and/or discard, and editors to track and check the evolution of their journals ${ }^{[3,4]}$. However, the impact factor is also being used to evaluate research performance and is applied at all organizational levels: authorship, institution, country/ region, research field or journal, which distorts its application. To compensate for this, in 2018 the JCR reviewed journal profiles with a richer data context. One example is the bar chart that provides the value of the impact factor in the Percentile Rank in Category item, allowing the quartile to be viewed quickly.

When analyzing the impact factor data from Brazilian Journal of Cardiovascular Surgery (BJCVS), they were promising: the impact factor was 0.805 (Figure 1) and the journal is classified in the following categories: Cardiac \& Cardiovascular System and Surgery in Q4 quartile (Figure 2). Regarding the contribution by country/region and organization, the highlight is for Brazil, which shows that we are still the majority of authors and readers of the journal (Figure 3).
BJCVS believes it is on the right track by prioritizing the quality of its publications and a structure that protects the authenticity of published work, what is reflected in the journal indicators.

\section{Articles in this Issue}

This issue of BJCVS presents a blind peer-reviewed selection of 20 papers that were selected by order of acceptance: 11 original papers, 1 review article, 4 selected case reports and 1 letter to the editor.

\section{Paulo Roberto B. Evora}

(iD) https://orcid.org/0000-0001-9631-946X

'Editor-in-Chief Interim - BJCVS

Faculdade de Medicina de Ribeirão Preto da Universidade de São Paulo (FMRP-USP), Ribeirão Preto, SP, Brazil.

\section{Andreia C. Feitosa do Carmo}

(iD) https://orcid.org/0000-0002-0387-7946

${ }^{2}$ Hospital São Paulo, Escola Paulista de Medicina da Universidade Federal de São Paulo, (EPM - UNIFESP), São Paulo, SP, Brazil.

\section{Camila Sáfadi Alves Gonçalves}

(iD) https://orcid.org/0000-0003-0611-7229

${ }^{3}$ Sociedade Brasileira de Cirurgia Cardiovascular, São Paulo, SP, Brazil.

\section{Domingo M. Braile}

(iD) https://orcid.org/0000-0001-7704-2258

${ }^{4}$ Editor-in-Chief - BJCVS

Faculdade de Medicina de São José do Rio Preto (FAMERP), São José do Rio Preto, SP, Brazil and Universidade de Campinas (UNICAMP), Campinas, SP, Brazil. 
2017 Journal Impact Factor \& percentile rank in category for:
BRAZILIAN JOURNAL OF CARDIOVASCULAR SURGERY

\section{0,805}

2017 Journal Impact Factor

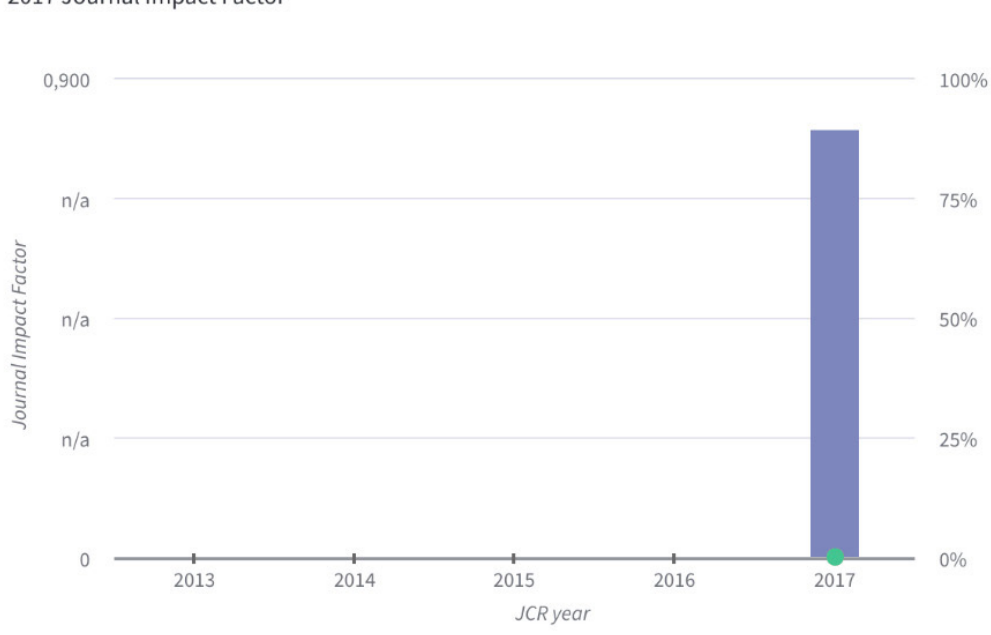

LEGEND

JIF

CARDIAC \&

CARDIOVASCULAR

SYSTEMS

SURGERY

Fig. 1 - Impact Factor of BJCVS.

Rank 2017

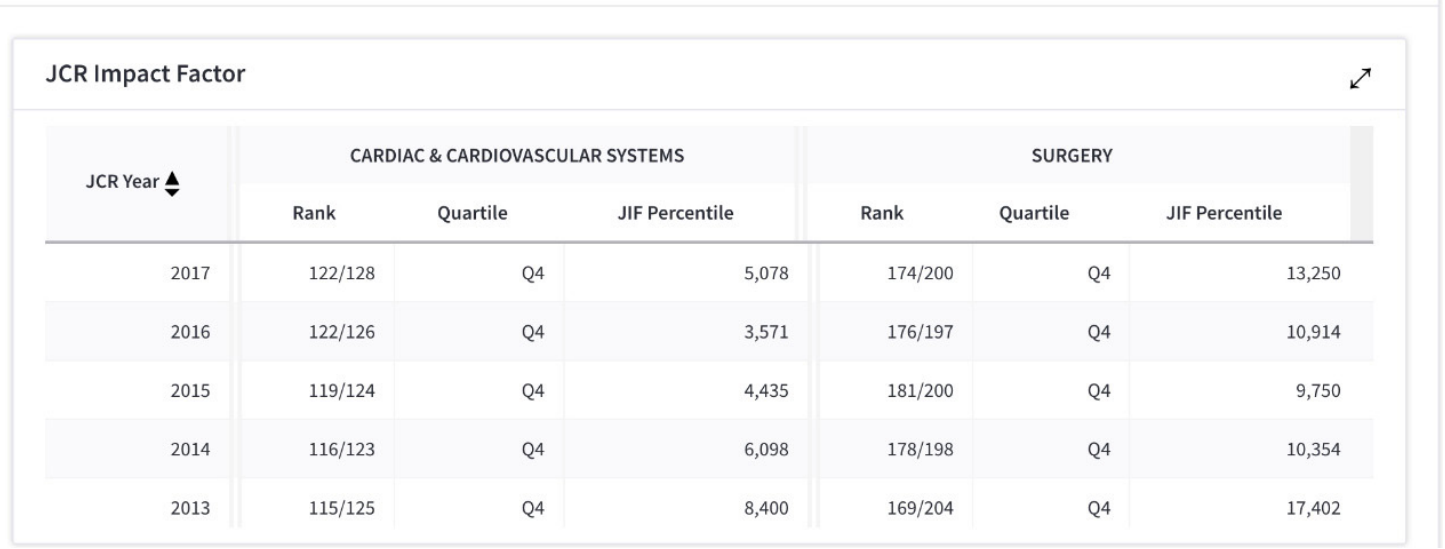

Fig. 2 - Category and Rank. 


\begin{tabular}{|c|c|c|c|}
\hline Contributions by country/region & $\nearrow$ & Contributions by organizations & $\nearrow$ \\
\hline country & count & organization & count \\
\hline 1. Brazil & 189 & 1. UNIVERSIDADE DE SAO PAULO & 61 \\
\hline 2. Turkey & 27 & 2. UNIVERSIDADE FEDERAL DE SAO PAULO (UNIFESP) & 16 \\
\hline 3. CHINA MAINLAND & 25 & 3. FUJIAN MEDICAL UNIVERSITY & 14 \\
\hline 4. USA & 18 & 4. LONGDEJING ST 389 & 13 \\
\hline 5. India & 11 & - UNIVERSIDADE ESTADUAL DE CAMPINAS & 13 \\
\hline 6. England & 7 & 6. UNIVERSIDADE FEDERAL DO RIO GRANDE DO SUL & 9 \\
\hline 7. Portugal & 6 & 7. BJ MED COLL & 7 \\
\hline 8. Colombia & 4 & 8. FAC MED SAO JOSE DO RIO PRETO FAMERP & 6 \\
\hline 9. Iran & 3 & - UNIVERSIDADE ESTADUAL PAULISTA & 6 \\
\hline - Italy & 3 & - UNIVERSITY OF ILLINOIS SYSTEM & 6 \\
\hline
\end{tabular}

Fig. 3 - Contribution by region and organizations.

\section{REFERENCES}

1. Garfield E. Journal impact factor: a brief review. CMAJ. 1999 Oct 19;161(8):979-80

2. Garfield E. Use of Journal Citation Reports and Journal Performance Indicators in measuring short and long term journal impact. Croat Med J. 2000 Dec;41(4):368-74.
3. Grzybowski A, Patryn R. Impact factor: Universalism and reliability of assessment. Clin Dermatol. 2017 May-Jun;35(3):331-334. doi:10.1016/j. clindermatol.2016.07.012.

4. Lippi G, Favaloro EJ, Guidi GC. The impact factor and journals in laboratory medicine. Clin Lab. 2009;55(1-2):49-52. 